\title{
Optimization of Microwave-Assisted Extraction of Residual Soybean Oil from Spent Bleaching Earth
}

\author{
Chanatip Dejkajorn ${ }^{l}$, Panawan Suttiarporn ${ }^{l}$, Hussanai Sukkathanyawat ${ }^{l}$, Kittisak Wichianwat ${ }^{l}$, Saichon $\operatorname{Sriphan}^{l}$ and \\ Thanarak Srisurat ${ }^{1}$ * \\ ${ }^{1}$ Faculty of Science, Energy and Environment, King Mongkut's University of Technology North Bangkok, Rayong \\ Campus, Rayong 21120, Thailand
}

\begin{abstract}
Spent bleaching earth (SBE) which is generated from bleaching process is a valuable industrial waste of edible vegetable oil production because of residual edible vegetable oil absorbed. The residual oil in spent bleaching earth can be recovered and reused for application in the industries such as the production of biodiesel and lubricant. Currently, microwave-assisted extraction (MAE) technique is widely used because this method has a shorter extraction time and less solvent consumption when compared with traditional methods. In this study, MAE combined with solvent reflux was optimized using solvent screening experiments and response surface methodology (RSM) to obtain the highest yield of MAE extraction of residual soybean oil from spent bleaching earth. The extraction yield of residual soybean oil obtained from selected solvent were hexane-ethanol mixture $(2: 1 \mathrm{v} / \mathrm{v}, 10.19 \%)>$ hexane-ethanol mixture $(1: 1 \mathrm{v} / \mathrm{v}, 10.00 \%)>$ hexane-ethanol mixture $(1: 2 \mathrm{v} / \mathrm{v}, 9.98 \%)>$ hexane-ethanol mixture $(1: 3 \mathrm{v} / \mathrm{v}, 9.83 \%)>$ hexane-ethanol mixture $(3: 1 \mathrm{v} / \mathrm{v}, 8.59 \%)>$ hexane $(8.17 \%)>$ acetone $(7.73 \%)$. The regression coefficient $(\mathrm{R}$-squared $=0.9852$ ) expresses the accuracy of the regression and indicates the relationship between experimental data and predicted result, with high regression coefficient close to 1 , which is remarkably desired. The experiment conditions for optimal MAE extraction of residual soybean oil from SBE were hexane-ethanol mixture $(2: 1 \mathrm{v} / \mathrm{v})$, liquid to solid ratio $15.56: 1 \mathrm{~mL} / \mathrm{g}$, extraction time $12.22 \mathrm{~min}$, and microwave power $350 \mathrm{~W}$. Under such conditions, the highest predicted value of the extraction yield of residual soybean oil was $10.43 \%$.
\end{abstract}

Keyword. microwave-assisted extraction, residual soybean oil, spent bleaching earth, response surface methodology.

\section{Introduction}

To remove impurities, raw vegetable oils are purified. The bleaching process is one of the purification processes in which soap materials and other impurities in the oil are removed by absorbents. The main absorbents are completely activated earth and activated carbon. It is collectively referred to as bleaching soil. After the bleaching earth is inactivated by impurities and clogging of its pores, it becomes a spent bleaching earth (SBE). SBE is a flammable waste material that can cause a fire if not properly stored or treated [1]. The waste contains 20 to $40 \%$ oils, fats, and pigments by weight, depending on various factors such as the processing technology and the type of oil [2]. The presence of oil in the clay, the potential leakage of fats into the water path, and the possibility of spontaneous combustion contribute to problems, hazards, and safety concerns, when SBE is disposed of in landfills. Moreover, the oil in the SBE results in dangerous pollution, constitutes an economic loss, and damages the environment. Furthermore, due to the rapid growth of industries and the concomitant increase in the rate of waste material production, the disposal of SBE has become a potential problem in countries that produce this waste. The recovery of oil from SBE reduces the cost of SBE disposal significantly, and the recovered oil may be reused. Due to its aromatic qualities, it may be reused in the refining process.

Oil extraction from SBE is applied to a wide range of techniques, such as solvent extraction, enzymeassisted aqueous extraction, and supercritical carbon dioxide extraction [3]. However, solvent extraction can extract a higher percentage of residual oil $(21 \%$ $\left.\mathrm{W}_{\text {oi }} / \mathrm{W}_{\mathrm{SBE}}\right)$ [4]. Soxhlet extraction with $\mathrm{n}$-hexane solvent is commonly used for vegetable oils extraction. Because of its high yield and extraction efficiency, Soxhlet extraction is widely used to extract oil $[3,5]$. Soxhlet extraction has longer extraction times, higher energy consumption, possible compound degradation, lower extraction rates due to lower mechanical pressure, and may have a negative environmental impact [6].

Microwave-assisted extraction (MAE) is a modern method for extracting essential oils, fats, and oils [7]. The application involves the direct action of waves on materials, which can convert a component of the absorbed electromagnetic energy to heat energy. Unlike traditional heating methods, which rely on conduction and convection, this causes a long extraction time. As a

*Corresponding author : thanarak.sciee.kmutnb.ac.th 
result, thermal energy is lost to the environment. When compared to soxhlet extraction, this heating process can significantly minimize extraction time (typically less than 30 minutes) [8]. The principle of heating using a microwave is based upon its direct impact on polar samples and solvents [9]. Ethanol is produced by fermenting biological materials and is derived from renewable resources. Therefore, ethanol has been considered as a possible green solvent alternative to hexane because it has more polarity than hexane and has long been used for oil extraction in the production of sesame seed cake, rice bran, and radish seed. Moreover, ethanol has been offered as an environmentally friendly extraction solvent of plant oil because it produces higher extraction rates and uses less solvent [10].

In this context, it represents a challenge for the development of more efficient methods of extracting residual oil from spent bleached earth. Meanwhile, microwave technologies have proven to be effective at accelerating the extraction of solvent from matrices and using less solvent. Moreover, the residual oil that was removed from the spent bleaching earth can be used to produce biodiesel or consumed after a deodorized process [11]. On the other hand, after removing the residual oil from the spent bleached earth, SBE can be reused in the bleaching process again [12] or as heavy metal absorbents [13]. The objective of this research was to use microwave-assisted extraction (MAE), which is an efficient and environmentally friendly technique, and select an alternative solvent for residual soybean oil extraction, as well as to use the response surface methodology for variable optimization in the MAE process to achieve maximum extraction yield of residual oil. Then, the optimum residual soybean oil response obtained from MAE was compared with that of the soxhlet traditional technique in terms of oil yield profile.

\section{Material and Methods}

\subsection{Materials}

Spent bleaching earth (SBE) received from Sime Darby Oils Morakot Pub Co., Ltd., Thailand. Hexane, acetone, and ethanol, used as extraction solvents, and other chemicals are analytical-grade reagents. They were purchased from DUKSAN (ASIA Chemie Co.,Ltd., Thailand).

\subsection{Selection of solvent in MAE}

A $1,000 \mathrm{~mL}$ flat-bottom flask containing different solvents $(150 \mathrm{~mL})$ and spent bleaching earth $(10 \mathrm{~g})$ is fitted with a microwave-assisted extractor (EME2024MW, Electrolux Thailand Co., Ltd., Thailand). The heating was turned off after 10 minutes, and the remaining soybean oil was recovered from the solution with a rotary vacuum evaporator. The residual soybean oil was then dried in an oven at $105^{\circ} \mathrm{C}$ until it reached a constant weight, removing any remaining solvent and moisture. Finally, the oil was weighed after cooling in a desiccator. The MAE yield of residual soybean oil was calculated as equation 1 .

$Y=\left(W_{\text {oil }} / W_{S B E}\right) * 100$

Where, $\mathrm{Y}$ is the MAE yield of residual soybean oil (\%); $\mathrm{W}_{\text {oil }}$ is weight of oil extraction and $\mathrm{W}_{\mathrm{SBE}}$ is the weight of SBE.

\subsection{Oil extraction methods}

\subsubsection{Soxhlet extraction}

The total residual soybean oil content of spent bleaching earth was determined by soxhlet extraction, by the Association of Official Analytical Chemists (AOAC). Briefly, $200 \mathrm{~mL}$ of hexane and $10 \mathrm{~g}$ of the spent bleaching earth were heated to reflux for 8 hours. The heating was then turned off, and the residual oil was recovered using a rotary vacuum evaporator. The residual soybean oil was then dried in an oven at $105^{\circ} \mathrm{C}$ until it reached a constant weight, removing any remaining solvent and moisture. Finally, the oil was weighed after cooling in a desiccator [14]. This method extracted total oil content from the SBE $1.13 \pm 0.38 \mathrm{~g}$ (11.30\% of the SBE by weight).

\subsubsection{MAE-single factor experiments}

Microwave-assisted extractor was performed at ambient in a $1,000 \mathrm{~mL}$ flat bottom flask. Various extraction time $(5,10,15,20$, and $30 \mathrm{~min})$, liquid to solid ratios (10:1, $15: 1,20: 1,25: 1$, and $30: 1 \mathrm{~mL} / \mathrm{g}$ ), and microwave power $(210,280,350,420$, and $490 \mathrm{~W})$ were applied. To obtain consistent residual soybean oil yields, the mixtures were dried using a rotary evaporator to remove the solvent. The extracted oil is then dried in an oven to keep a constant residual soybean oil. All experiments were performed in triplicate. The extraction yield of residual soybean oil was assessed according to equation 1.

\subsection{Optimization of MAE parameters by RSM}

Operational conditions were optimized using response surface methodology (RSM) coupled with the BoxBehnken design (BBD) to further evaluate the main factors affecting the MAE process. Based on singlefactor tests, extraction time $\left(\mathrm{X}_{1}: 5-15 \mathrm{~min}\right)$, liquid to solid ratios $\left(\mathrm{X}_{2}: 10: 1-20: 1 \mathrm{~mL} / \mathrm{g}\right)$, and microwave power $\left(\mathrm{X}_{3}: 280-420 \mathrm{~W}\right)$ were used as the MAE independent variables (Table 1). Residual soybean oil yield (Y) was selected as a dependent variable. Extraction yields were obtained under different conditions according to the 15 runs of experimental design. The experiments were performed in triplicate. The second-order polynomial model was fitted to MAE experiment data. The quadratic equation was given as equation 2. 
$\mathrm{Y}=\mathrm{b}_{0}+\mathrm{b}_{1} \mathrm{X}_{1}+\mathrm{b}_{2} \mathrm{X}_{2}+\mathrm{b}_{3} \mathrm{X}_{3}+\mathrm{b}_{11} \mathrm{X}_{1}^{2}+\mathrm{b}_{22} \mathrm{X}_{2}^{2}$

$+b_{33} X_{3}^{2}+b_{12} X_{1} X_{2}+b_{13} X_{1} X_{3}+b_{23} X_{2} X_{3}$

where, $\mathrm{Y}$ is the response variable; $\mathrm{X}_{1}, \mathrm{X}_{2}$, and $\mathrm{X}_{3}$ represents the MAE independent variables; $b_{0}$ is the intercept; $b_{1}, b_{2}$, and $b_{3}$ are linear coefficients; $b_{11}, b_{22}$, and $b_{33}$ are quadratic coefficients; $b_{12}, b_{13}$, and $b_{23}$ are interaction coefficients. MAE conditions were optimized using the software Minitab 18 (trial version, Minitab Inc., State College, PA, USA).

\subsection{Statistical analysis}

The extraction of the residual soybean oil was performed three times. All experimental data is represented using mean and standard deviation. The ANOVA procedure was used to perform analysis of variance, as well as Duncan's multiple comparison test to determine significant differences $(\mathrm{p}<0.05)$ among the means using SPSS (version 26, IBM Institute Inc., USA). Minitab 18 was used to operate RSM analysis. To determine the model's significance and the best conditions for extracting residual soybean oil from spent bleaching earth, an analysis of variance (ANOVA) was used. The significance level was set at $\mathrm{p}<0.05$.

Table 1. Levels of the independent variables in the BoxBehnken designs (BBD)

\begin{tabular}{lcccc}
\hline \multicolumn{1}{c}{ Independent variables } & Code & \multicolumn{3}{c}{ Level } \\
\cline { 3 - 5 } & & -1 & 0 & 1 \\
\hline Extraction time $(\mathrm{min})$ & $\mathrm{X}_{1}$ & 5 & 10 & 15 \\
Liquid to solid ratio $(\mathrm{mL} / \mathrm{g})$ & $\mathrm{X}_{2}$ & $10: 1$ & $15: 1$ & $20: 1$ \\
Microwave power $(\mathrm{W})$ & $\mathrm{X}_{3}$ & 280 & 350 & 420 \\
\hline
\end{tabular}

\subsection{Free fatty acid analysis}

Free fatty acid value in oil from SBE was estimated by the titration AOCS Official Method Ca 5a-40 [15]. A 250-mL Erlenmeyer flask was filled with extracted oil soluble in ethanol solvent at $60{ }^{\circ} \mathrm{C}$, and phenolphthalein solution (3- 5 drops) was added to the sample solution and stirred. The solution was titrated with $\mathrm{KOH} 0.1 \mathrm{~N}$ drop by drop until the pink color appeared for 10 seconds, which was the endpoint. FFA content in fats and oils was calculated as a percentage. The free fatty acid was calculated as equation 3 .

$\% F F A=\left(V^{\prime} N^{\prime} 28.2\right) / W_{S B E}$

Where, $\mathrm{V}$ is the alkali volume; $\mathrm{N}$ is the alkali normality and $\mathrm{W}_{\mathrm{SBE}}$ is the weight of SBE.

\section{Results and discussion}

\subsection{Selection of solvent in MAE}

The effects of different solvents on the extraction yield of oil are show in Fig. 1. As alternative oil extraction options, hexane, acetone, ethanol, and hexane mixed ethanol at various volume ratios were considered, while all other factors were kept constant (10 g SBE with 150 $\mathrm{mL}$ solvent in a microwave for $10 \mathrm{~min}$ at power $350 \mathrm{~W}$ ). Using mixture of hexane and ethanol $(2: 1 \mathrm{v} / \mathrm{v})$ gave a higher extraction yield of oil shown in Fig. 1. This is due to the fact that the type of solvent employed in MAE is important. The microwave absorption capacity of a solvent is determined by type, and the solubility of the target molecule should be considered when selecting a solvent for MAE. Although ethanol has a high polarity which always allows microwave radiation to be absorbed, residual oil has limited solubility. Hexane has a weak polarity, but its increased residual oil solubility [16]. The effect of a mixture of hexane and ethanol on oil extraction yield was investigated in order to improve oil extraction yield. The extraction yield of oil obtained with a mixture of hexane and ethanol was higher than that achieved with a single solvent, with the maximum extraction yield of oil obtained by a 2:1 volume ratio of hexane and ethanol. According to the previous study, using a mixture of hexane and ethanol in the MAE of peony seed oil increased oil yield significantly when compared to using only one solvent [17]. As a result, a mixture of hexane and ethanol $(2: 1 \mathrm{v} / \mathrm{v})$ was utilized for further testing to maximize the MAE.

\subsection{Optimization of single-factor extraction conditions}

\subsubsection{Effect of extraction time on the oil yield}

One of the important variables influencing the extraction yield obtained from the MAE process is extraction time. Over-exposure to microwave radiation causes the extraction system to overheat, as well as the lengthened process time might raise the production cost [18]. The impact of extraction time on the MAE yield of residual soybean oil from SBE is shown in Fig. 2a. It can be observed that the extraction time increases from 5 to 10 minutes, the oil yield increases rapidly. It could be due to the rapid dissolution of oil solutes emanating from the surface of SBE. The highest oil yield was $10.43 \pm$ $0.06 \%$, which was observed at 10 minutes. After that, the oil yield remained constant over time.

\subsubsection{Effect of liquid to solid ratio on the oil yield}

The liquid to solid ratio has a significant impact on the oil MAE process. The extraction of oil yield from SBE is influenced by solvent volume, which can affect residual soybean oil yield in two different ways. Fig. 2 b. shows the yield of oil from SBE extracted using various solvent to $\mathrm{SBE}$ ratios from $10: 1$ to $30: 1 \mathrm{~mL} / \mathrm{g}$. With a liquid to solid ratio of $15: 1 \mathrm{~mL} / \mathrm{g}(10.33 \pm 0.05 \%)$, the extraction yield of residual soybean oil from SBE was found to be the highest and remained constant as the liquid to solid ratio was increased. This was significant because it meant that, while a certain amount of solvent was 
desirable for SBE oil extraction, excessive solvent might result in higher costs [19].

\subsubsection{Effect of microwave power on the oil yield}

The quantity of energy transmitted per unit of time is measured as microwave power. Microwave power was used to heat the bleaching earth. The oil and matrix were disrupted by its driving force, allowing the oil to diffuse out and dissolve in the solvent. When microwave radiation is higher, it causes the excessive temperature in the extraction process. In Fig. 2c., when the microwave power was raised from $280 \mathrm{~W}$ to $350 \mathrm{~W}$, the oil extraction yield increased from $9.10 \pm 0.31 \%$ to $10.02 \pm$ $0.03 \%$, followed by a decrease in the oil yield at $420 \mathrm{~W}$ and $490 \mathrm{~W}$. An increase in microwave power usually improves and heats, resulting in higher oil yields. On the other hand, increased microwave radiation power causes the extraction system to overheat, causing the solvent to evaporate [20].

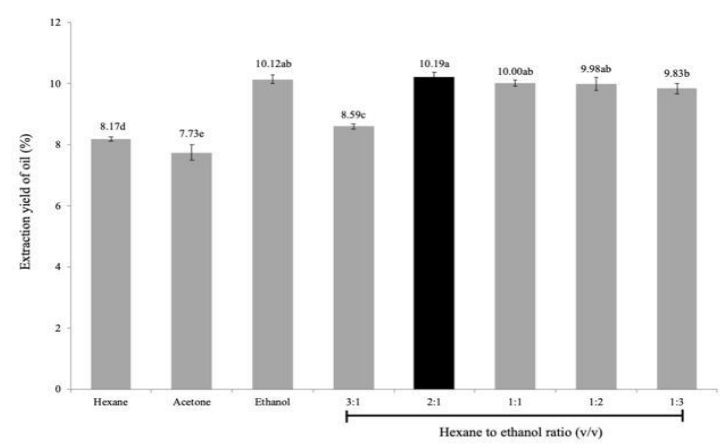

Fig. 1. Effect of solvent type on extraction yield of residual soybean oil.

\subsection{Optimization of parameters by RSM}

A Box-Behnken design was applied to develop a correlation between the extraction time $\left(\mathrm{X}_{1}\right)$, solvent to SBE ratio $\left(\mathrm{X}_{2}\right)$, and microwave power $\left(\mathrm{X}_{3}\right)$ to optimize the yield of residual soybean oil. Table 2 shows the variations in the corresponding coded values of three MAE parameters, as well as the MAE yield response based on experimental runs of oil extraction. The extraction yield of residual soybean oil was in the range of 5.52 to $10.40 \%$ in the experiments. The polynomial equation of MAE yield with the coefficients of the full regression model equation and their statistical significance were investigated using the software Minitab 18 for multiple regression analysis. The final model for extraction yield of oil in terms of coded values is presented in equation 4. The positive symbol in front of the terms expressed a synergistic effect, while the negative symbol expressed an antagonistic effect.

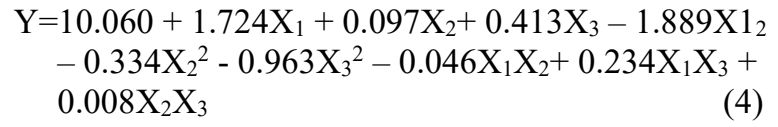

Where $\mathrm{Y}$ is the extraction yield of oil, $\mathrm{X}_{1}$ is the extraction time, $\mathrm{X}_{2}$ is the liquid to solid ratio, and $\mathrm{X}_{3}$ is the microwave power, respectively.
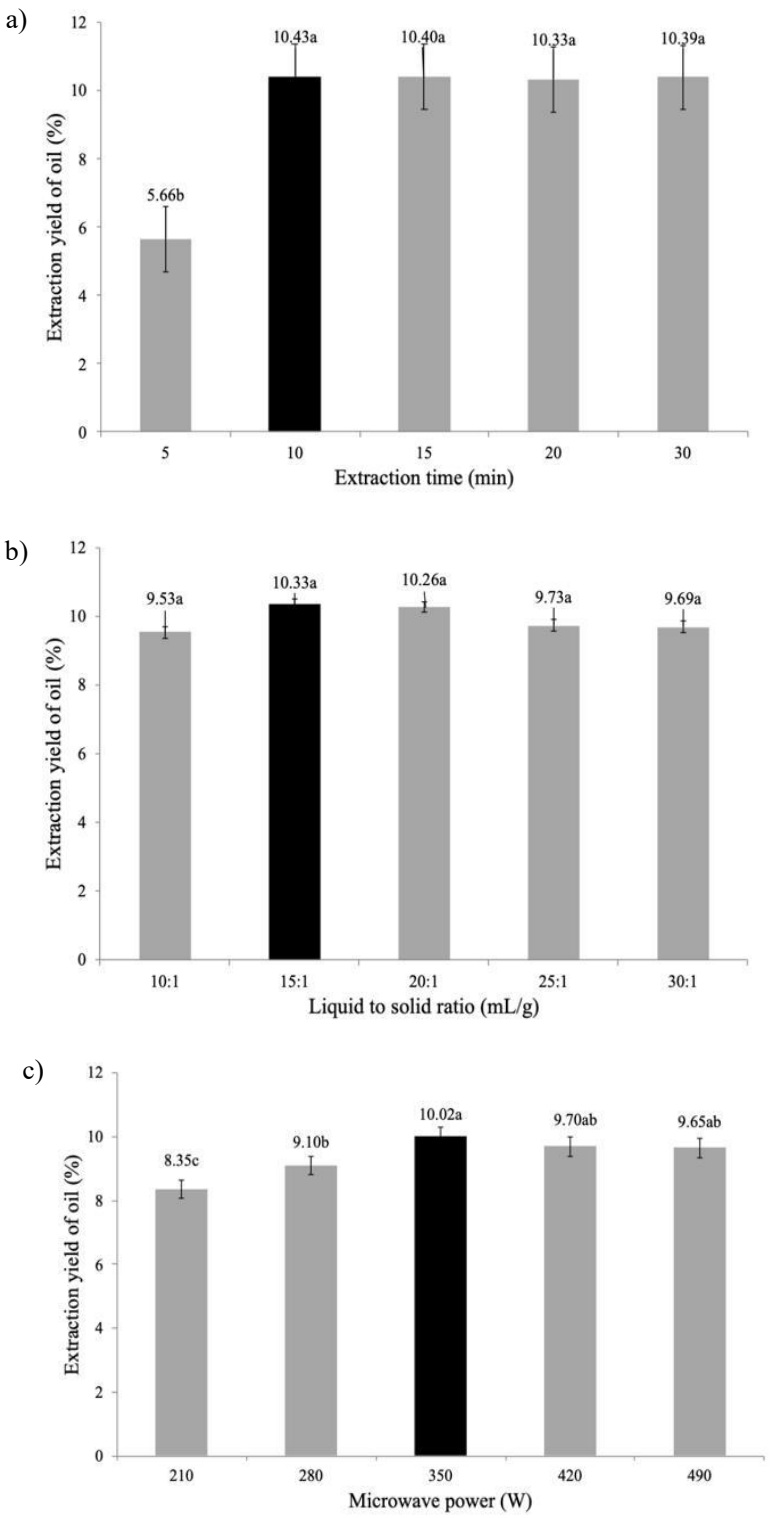

Fig. 2. Effects of extraction time (a), liquid to solid ratio (b), microwave power (c) on the extraction yield of residual soybean oil.

\subsubsection{Statistical analysis of the model}

Table 3 illustrates the ANOVA results for the fitted quadratic polynomial model of MAE yields of residual soybean oil. Model terms of oil extraction with $\mathrm{p}$-values less than 0.05 are significant: in this model, $\mathrm{X}_{1}, \mathrm{X}_{3}, \mathrm{X}_{12}$ and $\mathrm{X}_{23}$ are significant terms. The lack-of-fit $\mathrm{p}$-value was 0.09 ( $\mathrm{p}$-value $>0.05$ ), indicating that the model equation for oil extraction is appropriate for predicting residual soybean oil yield from SBE. For residual soybean oil yield, the coefficient of determination $\left(\mathrm{R}^{2}\right)$ was 0.985 , suggesting good model effectiveness: the predicted $\mathrm{R}^{2}$ of 0.822 agrees with the study $\mathrm{R}^{2}$ of 0.958 [21]. As a result, the regression equation can be used to decide which one 
the optimum condition is for the MAE process of residual oil from spent bleaching earth.

\subsubsection{Analysis of the contour plot and response surface}

The response surfaces of MAE oil yield can be plotted as three-dimensional plots and contour plots, as shown in Fig. 3-5., which shows the response surface for oil extraction yield as a function of two parameters with a fixed third variable. The interaction of extraction time $\left(\mathrm{X}_{1}\right)$ and solvent to $\mathrm{SBE}$ ratio $\left(\mathrm{X}_{2}\right)$ on oil extraction yield is shown in Fig. 3. The oil yield increased to its maximum when the extraction time was between 10 and 15 minutes and the liquid to solid ratio was between 10:1 and $20: 1 \mathrm{~mL} / \mathrm{g}$, as shown by the quadratic surface. However, increased energy losses come at a cost, and a large solvent volume would make it difficult to remove the solvent and waste it, so it was critical to maintain a proper extraction time and liquid to solid ratio [22]. Fig. 4 illustrates the surface plot and contour plot for the interactive effect of solvent to $\mathrm{SBE}$ ratio $\left(\mathrm{X}_{2}\right)$ and microwave power $\left(\mathrm{X}_{3}\right)$ on oil extraction yield, liquid to solid ratio and microwave power provided obvious secondary effects, and oil yield increased to the maximum when the solvent to SBE ratio was between $13: 1$ and $18: 1 \mathrm{~mL} / \mathrm{g}$ and microwave power was between 350 and $390 \mathrm{~W}$. The surface plot and contour plot for the interactive effect of extraction time $\left(\mathrm{X}_{1}\right)$ and microwave power $\left(\mathrm{X}_{3}\right)$ on the extraction yield of oil can be seen in Fig. 5.
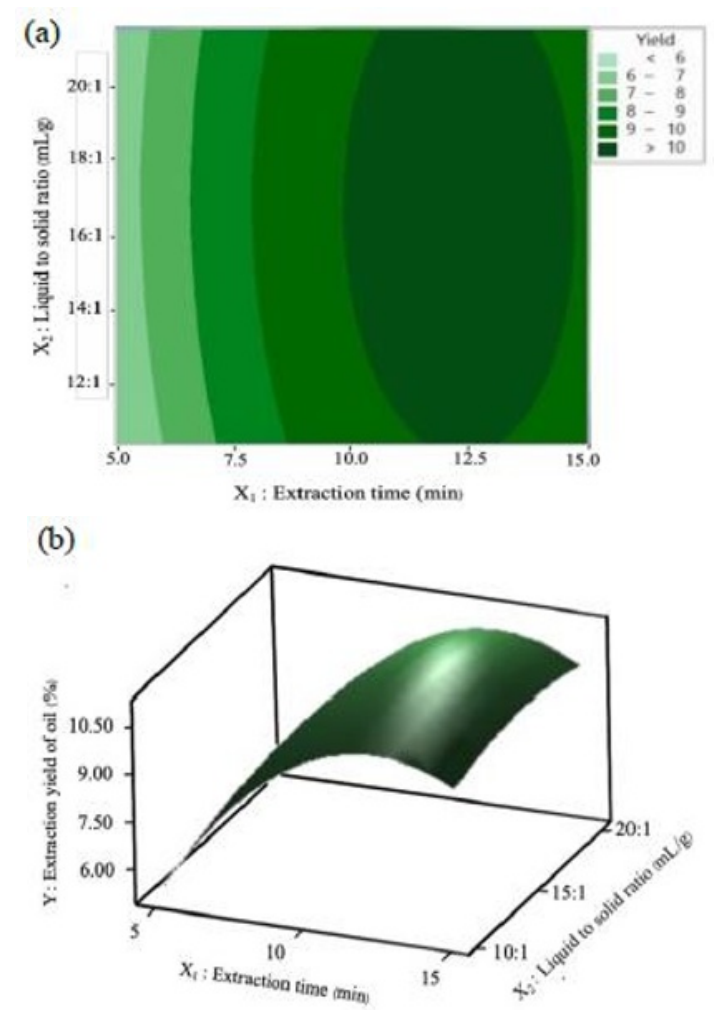

Fig. 3. Contour (a) and 3D surface (b) plots for the effects of extraction time and liquid to solid ratio on the yield of oil.
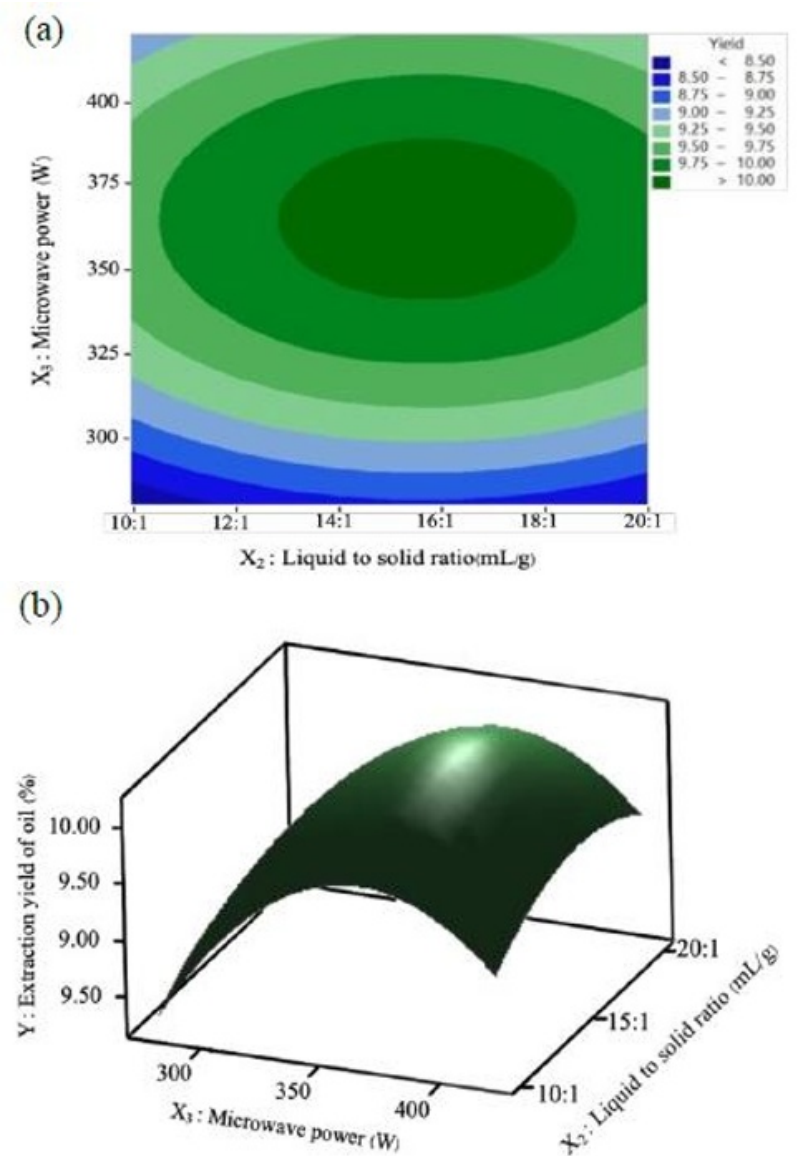

Fig. 4. Contour (a) and 3D surface (b) plots for the effects of liquid to solid ratio and microwave power on the yield of oil.

\subsection{Optimal conditions and verification of the models}

One of the main goals of this research was to optimize conditions for extracting residual soybean oil from SBE The extraction oil yield was found to be significantly affected by extraction time $\left(\mathrm{X}_{1}\right)$ and microwave power $\left(\mathrm{X}_{3}\right)$. In the range of extraction time $(10-15 \mathrm{mins})$ and microwave power $(325-400 \mathrm{~W})$, the highest extraction oil yield was obtained when both variables were increased. generated during the purification of edible oil. Using Minitab 18, the fitted model was optimized to select the optimal conditions for extracting oil from SBE using mixed solvents (hexane: ethanol 2:1 v/v). As shown in Table 4, the maximum extraction oil yield was $10.43 \%$ (actual value) for mixture of hexane and ethanol $(2: 1 \mathrm{v} / \mathrm{v})$ with an extraction time of 12.22 minutes, a solvent to $\mathrm{SBE}$ ratio of $15.56 \mathrm{~mL} / \mathrm{g}$, and a microwave power of $350 \mathrm{~W}$, For the MAE of residual soybean oil, the second-order polynomial model suggested a maximum oil yield of $10.46 \%$. The desirable value of 1.000 was used to measure the optimum conditions and predicted value. The verification of the oil yield model is shown in Table 4 . with a $0.286 \%$ error, the actual oil yield was close to those predicted by the models, according to the validated results. This indicated that the defined response model was accurate at predicting oil yield. 


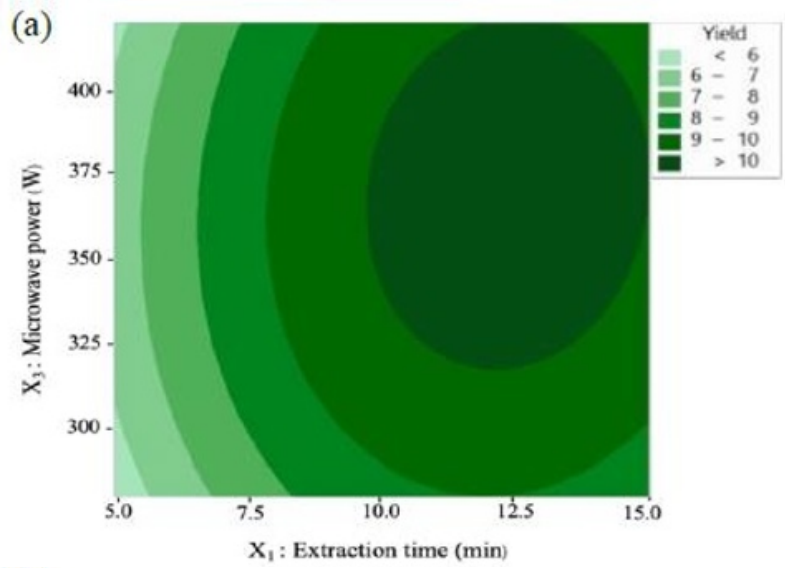

(b)

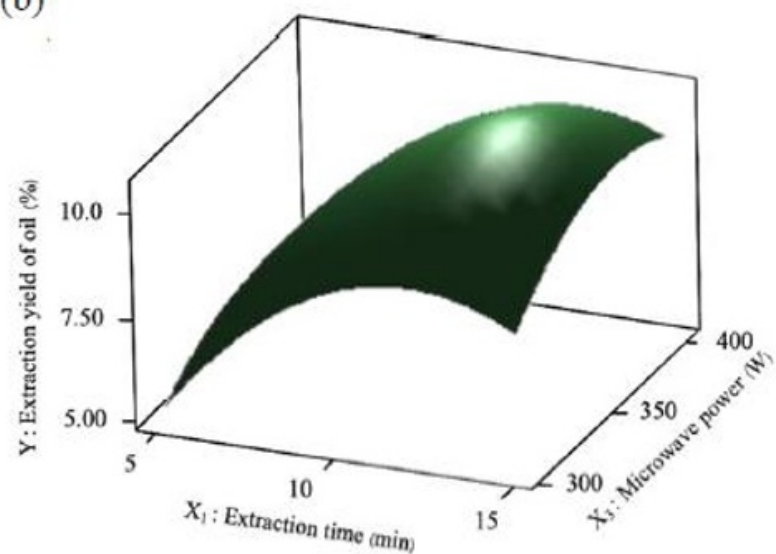

Fig. 5. Contour (a) and 3D surface (b) plots for the effects of extraction time and microwave power on the yield of oil.

\subsection{Free fatty acid analysis}

Table 5 shows the properties of residual oil obtained MAE process. The amount of free fatty acids present, which are products of oil and fat hydrolysis. Oils with a high content of free fatty acids are prone to oxidation and odor. The extraction of residual oils with ethanol has a darker color. It contains a lot of free fatty acids. While the residual oil extracted from non-polar solvent (hexane) are yellow, and contains low free fatty acids $[14,23]$. The residual soybean oil, on the other hand, must be deodorized before it can be consumed. To reduce the amount of free fatty acids to less than $1 \%$ [24]. It must be done if it is to be used as a raw material for biodiesel production. Before entering the transesterification process, esterification is used to reduce the amount of free fatty acids to less than $2 \%$ [25].

\subsection{Comparison of MAE with the Soxhlet method}

The comparison of yield profiles of residual soybean oil extracted using the MAE and soxhlet processes is presented in Fig. 6. At a five-minute, MAE extraction yields greater than soxhlet extraction $(5.62 \%$ and $1.91 \%$, respectively). This is due to the fact that microwave use a more efficient heat current. Microwave, unlike conventional conductive heating technology, may heat all samples practically simultaneously and at a faster rate [26]. The residual soybean oil yield from SBE increases with increasing microwave irradiation time until the plateau or equilibrium is reached. The residual soybean oil from $9.37 \pm 0.10 \%$ extracted $\mathrm{SBE}$ was recovered in 15 minutes by MAE, whereas the soxhlet requires 45 minutes $(8.83 \pm 0.11 \%)$ or more to reach equilibrium. These findings show significant time savings.

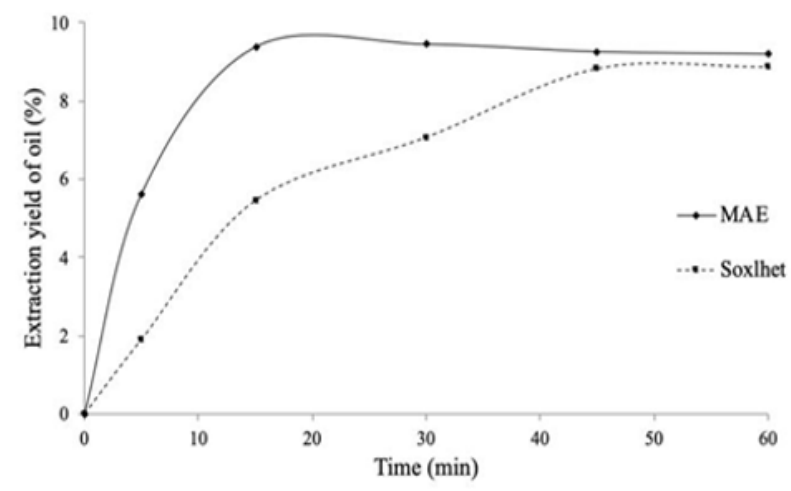

Fig. 6. Comparison of the yield profiles of microwave-assisted method (MAE) and soxhlet method.

\section{Conclusion}

From the selection of solvents, the mixture of hexane and ethanol $(2: 1 \mathrm{v} / \mathrm{v})$ is a high extraction yield of oil. The optimal condition for oil extraction was extraction time $12.22 \mathrm{~min}$, liquid to solid ratio $15.56: 1 \mathrm{~mL} / \mathrm{g}$, and microwave $350 \mathrm{~W}$, which has the amount of extraction yield of oil is $10.43 \%(92.30 \%)$. When comparing microwave-assisted extraction to the soxhlet extraction method, it was discovered that microwave-assisted extraction takes less time. The residual soybean oil extracted from spent bleaching earth can be recovered and reused in applications such as biodiesel and lubricants, as well as the reuse of spent bleaching earth in the bleaching process. It can also be utilized as a heavy metal absorbent.

\section{Acknowledgements}

This research was funded by Faculty of Science, Energy and Environment, King Mongkut's University of Technology North Bangkok. Contract no. SCIEEKMUTNB-64-005. The authors gratefully thank to Sime Darby Oils Morakot Pub Co., Ltd., Thailand for supporting spent bleaching earth. 
Table 2. MAE yield responses of BBD.

\begin{tabular}{|c|c|c|c|c|}
\hline Runs & $\begin{array}{c}\text { Extraction Time } \\
\left(\mathrm{X}_{1}, \mathrm{~min}\right)\end{array}$ & $\begin{array}{l}\text { Liquid to solid ratio } \\
\left(\mathrm{X}_{2}, \mathrm{~mL} / \mathrm{g}\right)\end{array}$ & $\begin{array}{c}\text { Microwave power } \\
\left(\mathrm{X}_{3}, \mathrm{~W}\right)\end{array}$ & $\begin{array}{c}\text { Extraction yield of oil } \\
(\mathrm{Y}, \%)\end{array}$ \\
\hline 1 & $1(15)$ & $1(20)$ & $0(350)$ & $9.64 \pm 0.31$ \\
\hline 2 & $-1(5)$ & $0(15)$ & $1(420)$ & $5.79 \pm 0.11$ \\
\hline 3 & $0(10)$ & $1(20)$ & $1(420)$ & $9.47 \pm 0.37$ \\
\hline 4 & $1(15)$ & $0(15)$ & $-1(280)$ & $8.15 \pm 0.20$ \\
\hline 5 & $1(15)$ & $0(15)$ & $1(420)$ & $9.35 \pm 0.74$ \\
\hline 6 & $0(10)$ & $-1(10)$ & $1(420)$ & $8.97 \pm 0.05$ \\
\hline 7 & $-1(5)$ & $-1(10)$ & $0(350)$ & $5.94 \pm 0.29$ \\
\hline 8 & $0(10)$ & $-1(10)$ & $-1(280)$ & $8.06 \pm 0.04$ \\
\hline 9 & $1(15)$ & $-1(10)$ & $0(350)$ & $9.83 \pm 0.23$ \\
\hline 10 & $0(10)$ & $0(15)$ & $0(350)$ & $10.40 \pm 0.11$ \\
\hline 11 & $0(10)$ & $0(15)$ & $0(350)$ & $9.90 \pm 0.91$ \\
\hline 12 & $0(10)$ & $0(15)$ & $0(350)$ & $9.87 \pm 0.13$ \\
\hline 13 & $0(10)$ & $1(20)$ & $-1(280)$ & $8.53 \pm 0.01$ \\
\hline 14 & $-1(5)$ & $0(15)$ & $-1(280)$ & $5.52 \pm 0.03$ \\
\hline 15 & $-1(5)$ & $1(20)$ & $0(350)$ & $5.93 \pm 0.04$ \\
\hline
\end{tabular}

Table 3. ANOVA statistics for response surface quadratic model of MAE yields of residual soybean oil.

\begin{tabular}{|c|c|c|c|c|c|c|}
\hline Source & $\begin{array}{l}\text { Sum of } \\
\text { squares }\end{array}$ & df & Mean square & $F$-value & $p$-value & Remarks \\
\hline Model & 41.1776 & 9 & 4.5753 & 37.10 & 0.000 & Significant \\
\hline Linear & 25.2266 & 3 & 8.4089 & 68.19 & 0.000 & Significant \\
\hline $\mathrm{X}_{1}$ & 23.7843 & 1 & 23.7843 & 192.86 & 0.000 & Significant \\
\hline $\mathrm{X}_{2}$ & 0.0753 & 1 & 0.0753 & 0.61 & 0.470 & \\
\hline $\mathrm{X}_{3}$ & 1.3670 & 1 & 1.3670 & 11.09 & 0.021 & Significant \\
\hline Square & 15.7228 & 3 & 5.2409 & 42.50 & 0.001 & Significant \\
\hline $\mathrm{X}_{1}{ }^{2}$ & 13.1731 & 1 & 13.1731 & 106.82 & 0.000 & Significant \\
\hline $\mathrm{X}_{2}{ }^{2}$ & 0.4130 & 1 & 0.4130 & 3.35 & 0.127 & \\
\hline $\mathrm{X}_{3}{ }^{2}$ & 3.4269 & 1 & 3.4269 & 27.79 & 0.003 & Significant \\
\hline 2-Way interaction & 0.2282 & 3 & 0.0761 & 0.62 & 0.633 & \\
\hline $\mathrm{X}_{1} \mathrm{X}_{2}$ & 0.0086 & 1 & 0.0086 & 0.07 & 0.802 & \\
\hline $\mathrm{X}_{1} \mathrm{X}_{3}$ & 0.2193 & 1 & 0.2193 & 1.78 & 0.240 & \\
\hline $\mathrm{X}_{2} \mathrm{X}_{3}$ & 0.0003 & 1 & 0.0003 & 0.00 & 0.963 & \\
\hline Error & 0.6166 & 5 & 01233 & & & \\
\hline Lack-of-fit & 0.4385 & 3 & 0.1462 & 1.64 & 0.400 & Not significant \\
\hline Pure error & 0.1781 & 2 & 0.0891 & & & \\
\hline Total & 41.7942 & 14 & & & & \\
\hline \multicolumn{7}{|c|}{$\mathrm{R}^{2}=0.985$, adj $\mathrm{R}^{2}=0.958$, pred $\mathrm{R}^{2}=0.822$} \\
\hline
\end{tabular}


Table 4. The optimal condition of MAE process and verification of the model.

\begin{tabular}{|c|c|c|c|c|c|c|}
\hline \multirow[b]{2}{*}{ Solvent } & \multirow{2}{*}{$\begin{array}{c}\text { Predicted } \\
) \%(\end{array}$} & \multirow{2}{*}{$\begin{array}{c}\text { Actual } \\
) \%(\end{array}$} & \multicolumn{3}{|c|}{ Optimal conditions } & \multirow{2}{*}{$\begin{array}{l}\text { Error } \\
) \%(\end{array}$} \\
\hline & & & $\begin{array}{l}\text { Extraction time } \\
\qquad) \min (\end{array}$ & $\begin{array}{l}\text { Liquid to solid ratio } \\
\qquad \mathrm{mL} / \mathrm{g}(\end{array}$ & $\begin{array}{c}\text { Microwave power } \\
\text { )W( }\end{array}$ & \\
\hline $\begin{array}{l}\text { Hexane to ethanol ratio } \\
\qquad) 2: 1 \mathrm{v} / \mathrm{v}(\end{array}$ & 10.46 & 10.43 & 12.22 & $15.56: 1$ & 350 & 0.286 \\
\hline
\end{tabular}

Table 5. Properties of soybean and extracted residual oil.

\begin{tabular}{ccccc}
\hline Property & \multirow{2}{*}{ Soybean oil } & Oil extracted from SBE & \multicolumn{2}{c}{ Oil extracted from SBE (soybean oil) } \\
\cline { 3 - 5 } & & (soybean oil) & hexane & H: E (2:1 v/v) \\
\hline Color & Yellow & Dark brown & Yellow-brown & Dark brown \\
Free fatty acid (\%) & $<1$ & 24.1 & 24.19 & 42.18 \\
Reference & {$[20]$} & {$[21]$} & \multicolumn{2}{c}{ This Work } \\
\hline
\end{tabular}

\section{References}

1. Hoy, Y.H. Edible Fats and Oils, (2000): 211-257

2. Z. Werner, Spent bleaching earth- practical solutions, INFORMS Journal on Applied Analytics, 5, 1375 (1994): 1375-1377

3. J. Zhong, Y. Wang, R. Yang, X. Liu, Q. Yang, X. Qin, The application of ultrasound and microwave to increase oil extraction from Moringa oleifera seeds, Industrial Crops and Products, 120, 1 (2018): 1-10

4. L.S. Kheang, C.S. Foon, C.Y. May, M.A. Ngan, A study of residual oils recovered from spent bleaching earth: their characteristics and applications, American Journal of Applied Sciences, 3, 2063 (2006): 2063-2067

5. F. Anwar, U. Rashid, Physico- chemical characteristics of Moringa oleifera seeds and seed oil from a wild provenance of Pakistan, Pak. Journal of Botany, 39, 1443 (2007): 1443-1453

6. D. B. Nde, D. Boldor, C. Astete, P. Muley, Z. Xu, Oil extraction from sheanut ( Vitellaria paradoxa Gaertn CF) kernels assisted by microwaves, Journal of food science and technology, 53, 1424 ( 2016) : 1424-1434

7. P. Cintas, E. Calcio- Gaudino, G. Cravotto, Pharmaceutical and nutraceutical compounds from natural matrices, Microwave-assisted extraction for bioactive compounds, 1, 181 (2012): 181-206

8. C.W. Huie, A review of modern samplepreparation techniques for the extraction and analysis of medicinal plants, Analytical and bioanalytical chemistry, 373, 23 (2002): 23-30

9. M. Letellier, H. Budzinski, L. Charrier, S. Capes, A. Dorthe, Optimization by factorial design of focused microwave assisted extraction of polycyclic aromatic hydrocarbons from marine sediment, Fresenius' journal of analytical chemistry, 364, 228 (1999): 228-237

10. M.C. Capellini, L. Chiavoloni, V. Giacomini, C.E. Rodrigues, Alcoholic extraction of sesame seed cake oil: Influence of the process conditions on the physicochemical characteristics of the oil and defatted meal proteins, Journal of Food Engineering, 240, 145 (2019): 145-152

11. B. P. Lim, G. P. Maniam, S. A. Hamid, Biodieselfrom adsorbed waste oil on spent bleaching clay using $\mathrm{CaO}$ as a heterogeneous catalyst. European Journal of Scientific Research. 33, 2 ( 2009) : 347-357.

12. M. Shahi, M. R. Sabour, A. Amiri, Cleaning spent bleaching clay through using solvent extraction method and RSM statistical approach. Cumhuriyet Üniversitesi Fen-Edebiyat Fakültesi Fen Bilimleri Dergisi, 36, 7, (2015): 23-40.

13. P. E. Dim, M. Termtanun, Treated Clay Mineral as Adsorbent for the Removal of Heavy Metals from Aqueous Solution, Applied Science and Engineering Progress, Online First (2021): 1-14.

14. A. Al. Zahrani, Y. Alhamed, Oil removal from spent bleaching clay by solvent extraction, Journal of Environmental Science \& Health Part A, 35, 1577 (2000): 1577-1590

15. Official Methods and Recommended Practices of the American Oil Chemists' Society, 4th edn., edited by D. Firestone, American Oil Chemists' Society, Champaign (1989): Ca 5a-40

16. H. Y. Zhou, C. Z. Liu, Microwave- assisted extraction of solanesol from tobacco leaves, Journal of Chromatography A, 1129, 135 (2006): 135-139

17. X. Sun, W. Li, J. Li, Y. Zu, C. Y. Hse, J. Xie, X. Zhao, Process optimisation of microwave- assisted extraction of peony ( Paeonia suffruticosa Andr.) seed oil using hexane- ethanol mixture and its characterisation, International Journal of Food Science \& Technology, 51, 2663 (2016) 2663-2673

18. O. R. Alara, N. H. Abdurahman, C. I. Ukaegbu, N. H. Azhari, Vernonia cinerea leaves as the source of phenolic compounds, antioxidants, and antidiabetic activity using microwave- assisted extraction technique, Industrial Crops and Products, 122, 533 (2018): 533-544

19. B. Yang, M. Zhang, H. Weng, Y. Xu, L. Zeng, 
Optimization of ultrasound assisted extraction ( UAE) of kinsenoside compound from Anoectochilus roxburghii (Wall.) lindl by response surface methodology (RSM), 25, 193 (2020): 193

20. Q. Chen, W. Dong, C. Wei, R. Hu, Y. Long, Combining integrated ultrasonic- microwave technique with ethanol to maximise extraction of green coffee oil from Arabica coffee beans, Industrial Crops and Products, 151, 112405 ( 2020) : 112405

21. K. Afshari, V. Samavati, S. A. Shahidi, Ultrasonicassisted extraction and in- vitro antioxidant activity of polysaccharide from Hibiscus leaf, International journal of biological macromolecules, 74, 558 (2015): 558-567

22. T. J. Mason, F. Chemat, M. Vinatoru. The extraction of natural produxts using ultrasound or microwaves, Current Organic Chemistry, 15, 2 (2011): 237-247

23. C. Lee, C. Seng, K. Liew, Solvent efficiency for oil extraction from spent bleaching clay, Journal of the American Oil Chemists' Society, 77, 1219 (2000) : 1219-1223
24. I. H. Rukunudin, P. J. White, C. J. Bern, and T. B. Bailey, A Modified Method for Determining Free Fatty Acids from Small Soybean Oil Sample Sizes, Journal of the American Oil Chemists Society, 75, 5 (1998): 563-568

25. Y. P. Huang, J. I. Chang, Biodiesel production from residual oils recovered from spent bleaching earth, Renewable Energy, 35, 1 (2010):269-274

26. B. Kaufmanm, P. Christen, Recent extraction techniques for natural products: microwaveassisted extraction and pressurised solvent extraction, Phytochemical Analysis: An International Journal of Plant Chemical and Biochemical Techniques, 13, 2 (2002): 105-113his research was funded by Faculty of Science, Energy and Environment.

27. A. Zamora, Fatty acid composition of some common edible fats and oils, Bethesda, MD: Scientific Psychic, (2005).

28. Y.P. Huang, J.I. Chang, Biodiesel production from residual oils recovered from spent bleaching earth, Renewable Energy, 35, 269 (2010): 269-274 